\title{
A MODULAR AND EXTENSIBLE DATA ACQUISITION AND CONTROL SYSTEM FOR TESTING SUPERCONDUCTING MAGNETS*
}

\author{
$\underline{\text { D.F. Orris }}^{+}$, R. Carcagno, FNAL, Batavia, IL
}

\begin{abstract}
The Magnet Test Facility at Fermilab tests a variety of full-scale and model superconducting magnets for both $\mathrm{R} \& \mathrm{D}$ and production. As the design characteristics and test requirements of these magnets vary widely, the magnet test stand must accommodate a wide range of Data Acquisition (DAQ) and Control requirements. Such a system must provide several functions, which includes: quench detection, quench protection, power supply control, quench characterization, and slow DAQ of temperature, mechanical strain gauge, liquid helium level, etc. The system must also provide cryogenic valve control, process instrumentation monitoring, and process interlock logic associated with the test stand. A DAQ and Control system architecture that provides the functionality described above has been designed, fabricated, and put into operation. This system utilizes a modular approach that provides both extensibility and flexibility. As a result, the complexity of the hardware is minimized while remaining optimized for future expansion. The architecture of this new system is presented along with a description of the different technologies applied to each module. Commissioning and operating experience as well as plans for future expansion are discussed.
\end{abstract}

\section{INTRODUCTION}

Power testing of superconducting magnets is dependant on two primary systems: one, the power supply system for supplying current and providing a means for extracting energy from the magnet; and two, the test stand cryogenic/quench DAQ and Control system. The later, which is the focus of this paper, includes DAQ, Programmable Logic Controller (PLC) monitoring and control, and quench management subsystems. The DAQ is used for reading out magnet temperature and strain sensors while the PLC system is used to monitor cryogenic sensors, control parameters such as liquid helium level, and process test stand interlock logic. The quench management system manages all magnet quench control hardware. Multiple power supply systems can exist, each having similar hardware architecture and the capability of multiplexing its power bus to multiple Test Stand Areas. Multiple Test Stand Areas exists and follow this extensible design: Each Test Stand Area can accommodate multiple test stands. These systems have all been standardized and can therefore be easily expanded. Hence the modular approach.

\section{TEST STAND AREA MODULAR ARCHITECTURE}

For a given test stand area, more than one test stand can be cooled down simultaneously. Therefore, test stand dependent PLC and DAQ hardware must be implemented for each test stand added to the test stand area. However, since only one power system can be bussed to a given test stand area at a time, it follows that only one of its test stands can be powered. The quench management system co-ordinates the quench detection and quench protection hardware and provides hardware permits that allow the power supplies and dump circuits to turn on. Since only one test stand can be powered at a time, only one quench management hardware system is required for a given test stand area. Local test stand area PLC controls insure the concurrence of the test stand selection of the power bus, the quench management signals, and the magnet protection Heater Firing Units (HFUs). Figure 1 shows the Test Stand Area Modular design.

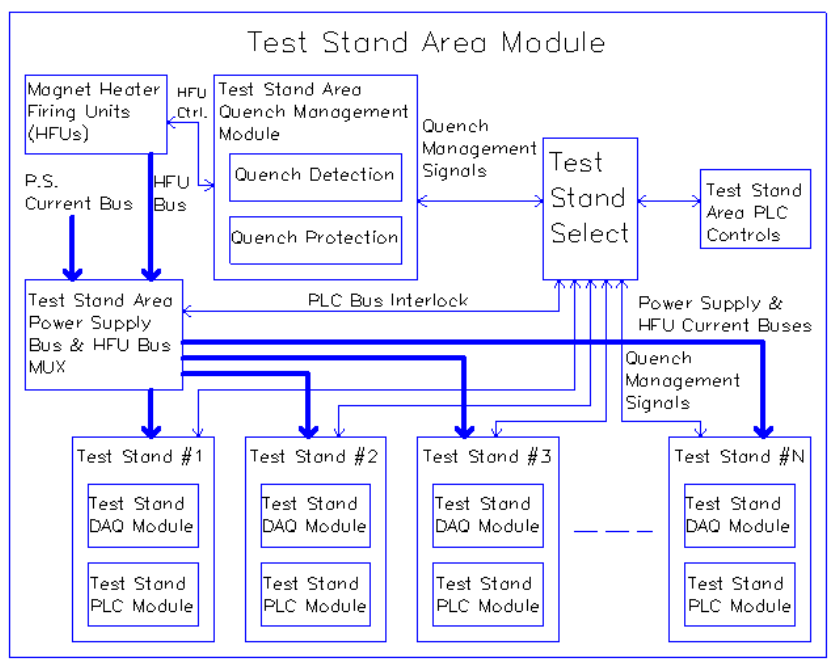

Figure 1: Test Stand Area Module DAQ \& Controls

\subsection{Test Stand Process Control Module}

Each test stand has a fixed set of sensors and actuators to establish and maintain test-operating conditions. Sensors typically include Temperature, Pressure, Vacuum, Helium

\footnotetext{
* Work supported by the United States Department of Energy

+orris@fnal.gov
} 
Liquid Level, and Switches. Actuators typically include on/off valves, control valves, and control relays. There are approximately 70 physical input/output $(\mathrm{I} / \mathrm{O})$ points in a test stand. Monitoring and control functions for this system are provided as a modular extension of the new 1500W Refrigerator Control System [1]. Table TBD shows Hardware and Software components of this industrial control system.

\begin{tabular}{|l|l|}
\hline \multicolumn{1}{|c|}{ Sub-System } & \multicolumn{1}{c|}{ Choice } \\
\hline $\begin{array}{l}\text { Programmable Logic } \\
\text { Controller (PLC) }\end{array}$ & Siemens 505-454 PLC \\
\hline $\begin{array}{l}\text { Input/Output (I/O) } \\
\text { Cards }\end{array}$ & Siemens 505 series \\
\hline Control Network & $\begin{array}{l}\text { Ethernet with TCP/IP in a routed } \\
\text { network }\end{array}$ \\
\hline $\begin{array}{l}\text { PLC Programming } \\
\text { Language }\end{array}$ & Siemens 505 SoftShop \\
\hline $\begin{array}{l}\text { Operator Interface } \\
\text { Software }\end{array}$ & FIX32 from Intellution \\
\hline Electrical Loops & $\begin{array}{l}\text { 24 VDC for discrete I/O, 4-20 mA } \\
\text { or 0-5 VDC for analog I/O. }\end{array}$ \\
\hline Temperature sensors & $\begin{array}{l}\text { Lakeshore CERNOX RTDs with } \\
\text { Model 234 temperature } \\
\text { transmitter cards and Pt RTDs } \\
\text { with Model 231P cards. }\end{array}$ \\
\hline $\begin{array}{l}\text { Liquid Helium Level } \\
\text { Probes }\end{array}$ & $\begin{array}{l}\text { American Magnetics } \\
\text { superconducting level sensors and } \\
\text { Model 135 liquid helium level } \\
\text { monitor }\end{array}$ \\
\hline External Interface & $\begin{array}{l}\text { ODBC interface to FIX32 real- } \\
\text { time database }\end{array}$ \\
\hline
\end{tabular}

Table TBD: Test Stand Process Control System

The test stand Control System is a completely independent module, with a separate PLC and SCADA node. Therefore, any failure of this system does not affect the refrigerator operability. The test stand control system is also completely independent from the test stand DAQ system. As a result, test stand operations are not affected by DAQ system downtime due to system reconfiguration, troubleshooting, or failures. Operators can bring up test stand operator displays from any operator station, so they can easily navigate between refrigerator control displays and test stand control displays. A software link allows two-way communication between the test stand control system database and the DAQ system, and an integrated pager system provides remote notification of alarm conditions to operators.

\subsection{Test Stand Data Acquisition Module}

The Test Stand DAQ System provides accurate 4-wire measurements of devices such as Temperature Sensors and Strain Gauges. Fast sampling of these devices is not typically required, so this system is designed for relatively low sampling frequencies $(\sim 8$ Channels/sec). Sensors are connected to the DAQ system using in-house designed and built 16-Channel "switchboxes". These switchboxes have several features to allow easy insertion or removal of a sensor to a current chain, chain current measurement via a precision shunt resistor, and test points for troubleshooting. Several sensors are typically connected to a current source chain for excitation, and the resulting sensor voltage is multiplexed via HP 1351 16-Channel FET Multiplexors to an HP 3458A Digital Multimeter (DMM) along with the chain current for accurate 4-wire resistance measurements. Software running in a VME processor configures the multiplexor (MUX) scanning list via the VME backplane. It also configures the DMM, and the programmable current sources via GPIB. The DMM triggers control the MUX advance to close the next channel in the scanning list, and after the voltage of all MUX channels in the scanning list have been measured by the DMM the results are transferred to the VME processor. The measured resistance is then converted to its corresponding value in engineering units using calibration curves previously loaded into the software. To minimize sensor self-heating effects the DAQ system optimizes the chain current so that the maximum sensor voltage is around $5 \mathrm{mV}$. In addition, the DAQ system performs polarity reversal for RTD measurements. As an example of the DAQ system accuracy, assuming that all RTD temperature sensors in a current chain are at around $4 \mathrm{~K}$ the absolute measurement error introduced by the DAQ system is approximately $\pm 4 \mathrm{mK}$.

The DAQ system is highly modular. Expandability is easily accomplished by adding more switchboxes and FET MUX VME modules, possibly more current sources, and modifying the software configuration to reflect the new configuration.

\subsection{Test Stand Area Quench Management System Module}

The Quench Management System performs the following tasks: it monitors/controls the magnet protection hardware, which includes the magnet heater power and the Dump extraction resistor; provides permits to the power system to turn on; and it monitors the magnet for the onslaught of resistive voltages (quench detection). In the event of a quench, it carries out the necessary actions in order to shut down the power supplies and extract the energy from the magnet while logging magnet voltage data at a fast rate in order to characterize the quench. The quench management signals have been standardized so this system can be easily multiplexed to several test stands.

The primary hardware component of the quench management system is the quench logic module (QLM). The QLM is an in-house built VME module and is the device that monitors the hardware status of the Dump resistor, the HFU load and charged statuses, and the magnet quench status. It also provides the power supply, 
the Dump, and the HFUs with the permits required to turn-on via contact closure. It also carries out the necessary logic for protecting the magnet, such as phasing back the power supply, firing the magnet protection heaters, and firing the Dump. User programmed delays may also be initiated. A heartbeat is also implemented to establish system integrity: Loss of a heartbeat causes a system trip similar to a quench. User interfaces are used to configure the QLM for magnet tests [2].

Since the magnet current often exceeds 10,000Amps, the response of the quench detection system must be very fast in order to prevent damage to the magnet -- typically less than $5 \mathrm{msec}$. Quench threshold detection is performed by the Digital Quench Detection (DQD) system [3]. The components used for DQD are a Motorola VME PowerPC, an Analogic DVX2503 ADC, and an in-house built anti-aliasing Bessel filter. The ADC samples at $11,520 \mathrm{~Hz}$. Since a 40tap FIR filter is implemented as a decimation filter via the PowerPC, a group delay of $\sim 1.7 \mathrm{msec}$ is incurred. Moreover, the anti-aliasing filter has a group delay of $0.23 \mathrm{msec}$, yielding a system total group delay of $\sim 1.93 \mathrm{msec}$. The decimation rate is typically set to $2400 \mathrm{~Hz}$, which limits the resolution of the quench decision to $\sim 0.4 \mathrm{msecs}$. This is a very reliable and easily configured system, however, Analog Quench Detection circuits (AQD) are also used as hardware backup for safety.

Other VME modules that are part of the Quench Management System include a VMIC 1160C Change of State (COS) and a Matrix MD-DAADIO module. The COS module, which is used for first fault detection/diagnostics, is optically coupled and has $1 \mathrm{msec}$ resolution. The DAADIO module is used for controlling and monitoring the HFUs and for reading out the Dump resistance. It includes digital I/O, Digital to Analog Converter (DAC), and an Analog to Digital Converter (ADC) all on the same board.

Pentek 4275B Sigma Delta ADCs, sampling at $7142 \mathrm{~Hz}$, are used to log magnet voltage tap data in order to determine quench location and propagation. Initialization and quench events for data saving are provided by the quench management software and a hardware quench trigger is provided by the QLM.

\subsection{Test Stand Selection}

Testing a magnet requires the implementation of a standard set of quench management signals. The HFU current bus and the power system current bus must also be connected to the test stand as well. It is imperative that all three systems are in concurrence in order to safely power the magnet and protect it in the event of a quench. This is done via a PLC system and hardwire interlock. When the quench management signals are selected for a particular test stand, both the HFU current bus and the power system current bus must be connected to the same test stand or the
PLC system will prevent the power supplies from turning on (Figure 1).

\subsection{Test Stand Area Expandability}

Since the Test Stand Area design has been standardized and is modular, the Quench Management signals, the power system bus, and the HFU current bus multiplexing are all part of its infrastructure. Therefore, expanding the number of test stands within the Test Stand Area is straightforward. Moreover, new test stands can have a unique set of instrumentation channels since the test stand DAQ and PLC modules are also standardized and independent of the test stand area. The Test Stands are therefore easily expandable as well.

\subsection{Operating Experience}

A Horizontal Test Stand Area for testing cryostated accelerator magnets has been built and tested. A full scale LHC quadrupole magnet has been cooled below the lambda point and power tested at currents exceeding 12Kamps. A second facility, used since 1997 for the testing of model magnets in a vertical cryostat (VMTF) [4], is now being upgraded to the new standardized design. Multiplexing of these two Test Stand Areas has been successfully tested and the addition of three existing test stands to the Horizontal Test Stand Area (future expansion) is planned for the near future.

\section{CONCLUSIONS}

The design and implementation of a DAQ and Controls system for testing superconducting magnets has been completed. A modular approach was taken in order to accompany future expansion of magnet test stands while remaining flexible to unique test stand instrumentation requirements. Since the hardware system developed has been standardized and designed for expansion, the reuse of key systems has reduced additional engineering, complexity, and subsequently the cost of new systems.

\section{REFERENCES}

[1] R. H. Carcagno and R. J. Rabehl, "Controls Upgrade of the Fermilab Magnet Test Facility 1500W Helium Refrigerator," Advances in Cryogenic Engineering, Vol. 45, p. 1795-1802, Plenum Press, New York, (2000).

[2] J.M.Nogiec, E.Desavouret, M.Lamm, D.Orris, S.Sharonov, J.Sim, "Architecture of a Software Quench Management System"PAC'01, Chicago, (2001).

[3] D.F. Orris, S. Feher, M.J. Lamm, J. Nogiec, S. Sharonov, M. Tartaglia, and J. Tompkins, "Digital Quench Detection System for Superconducting Magnets", PAC'99, New York, (1999)

[4] M.J. Lamm et al., "A New Facility to test Superconducting Accelerator Magnets", PAC'97, Vancouver, Canada, 1997 